\title{
Anaphylactic Shock in Patient with Hepatic Hydatic Cyst: An Experience at a Rural Hospital
}

\author{
Khapung R, ${ }^{1}$ Mahaset $\mathbf{N}^{1}$ \\ ${ }^{1}$ Department of anesthesia and critical care, Karnali Academy of Health Sciences, Jumla, Nepal. \\ Corresponding Author \\ Robin Khapung \\ Karnali Academy of Health Sciences, Jumla, Nepal \\ Email: robinkhapung@hotmail.com
}

\section{INTRODUCTION}

Hydatid disease is mainly caused by infection with the larval stage of the dog tapeworm Echinococcus granulosus. Infestation by hydatid disease in humans most commonly occurs in the liver (55$70 \%$ ) followed by the lung (18-35\%); the two organs can be affected simultaneously in about $5-13 \%$ of cases. ${ }^{1}$ Hydatid disease is endemic in many parts of the world, including India, Africa, South America, New Zealand, Australia, Turkey and Southern Europe ${ }^{1-3}$ Hydatid disease is more prevalent in rural areas where there is a closer contact between people and dogs and various domestic animals which act as intermediate vectors. Hydatid disease remains frequent in JUMLA. In Karnali Academy of Health sciences 26 surgeries for hydatid cyst was done between 2016-2018.

Hydatid cyst of liver in a child is a challenge to anesthesiologist in a remote city such as Jumla. Anaphylactic and anaphylactoid reactions during anesthesia are a major cause of concern for anesthesiologists. During the perioperative period, any symptomatology relating to sudden onset hemodynamic collapse or increased airway pressures during certain surgical procedures should raise suspicion of anaphylaxis. ${ }^{1,2}$ We report a case of intraoperative sudden anaphylaxis and its management.

\section{CASE REPORT}

12 years old child weighing $35 \mathrm{~kg}$ presented with complaints of pain in right upper part of abdomen that was accompanied by occasional non-projectile vomiting in the past two months. She also had history of fever for two months. Ultrasonography and computed tomography of the abdomen showed a cyst of the liver. Ultrasonography revealed three cystic lesions (two vesicular cystic anechoic lesions with approximate diameter 6 $\times 5 \mathrm{~cm}$ and $7 \times 6 \mathrm{~cm}$, and another cystic anechoic lesion with detached membrane about $7 \times 5 \mathrm{~cm}$ ) (water lily sign was positive). CT imaging revealed hepatomegaly with liver cysts of $64.5 \mathrm{~mm} \times 77 \mathrm{~mm}$ in segment VI and VII, another in segment IV measuring approximately $80.2 \mathrm{~mm} \times 61 \mathrm{~mm}$ and third in segment II measuring approximately $77.5 \times 64.7 \mathrm{~mm}$. of the liver. She was subsequently scheduled for partial cystectomy under general anesthesia.

Preoperative examinations of the cardiovascular and respiratory systems were normal. Laboratory evaluations, including hematological and biochemical profile, were within normal limits. She had no history of allergy.

Written informed consent was taken and was kept for nil per oral. The patient was premedicated with ranitidine $(150 \mathrm{mg}$ ) at night and the following morning. In the operation room, routine monitors (electrocardiogram, non-invasive automated blood pressure, pulse oximeter [SpO2]) were attached. Blood pressure was 126/76 mmHg, heart rate was 84 beats per minute and saturation of $100 \%$ was recorded. 
Premedication was done with injection glycopyrrolate $0.2 \mathrm{mg} \mathrm{I} / \mathrm{V}$ and Injection midazolam $0.5 \mathrm{mg}$ and Injection fentanyl $50 \mathrm{mcg}$ was given as analgesic. Anesthesia was induced with propofol $80 \mathrm{mg}$ and vecuronium $4 \mathrm{mg} I / \mathrm{V}$. Tracheal intubation was performed using a 7.0-mm internal diameter cuffed endotracheal tube. Temperature, capnography (EtCO2) and urine output monitoring were also initiated. Ventilation was maintained with intermittent positive pressure ventilation (volume control) at the rate of 12 breaths/min, and tidal volume of $350 \mathrm{~mL}$ and peak airway pressure of $22 \mathrm{~cm} \mathrm{h2o} \mathrm{(PaW).} \mathrm{Anesthesia} \mathrm{was} \mathrm{maintained}$ with isoflurane in oxygen, along with top-ups of vecuronium. The patient was hemodynamically stable at the onset of operation.

During surgery, when patient's liver was lifted in order to aspirate the cyst, there was sudden onset of hypotension. Blood pressure, returned to baseline after surgery was asked to stop and the liver was resumed to its normal position. Soon after the aspiration of the cyst, sudden and persistent desaturation (Sp02 20\%), hypotension (systolic blood pressure $40 \mathrm{mmHg}$ ), hypocarbia (EtCO2 10 $\mathrm{mmHg}$ ) and bradycardia (heart rate $44 / \mathrm{min}$ ) were noted. Surgeons were asked to stop the surgery. Isoflurane was discontinued.100\% oxygen was started. Atropine $0.6 \mathrm{mg}$ was given and fluid resuscitation was started. Persistent desaturation could not be corrected with institution of $100 \%$ oxygen. Hypotension did not respond to fluids, and peak airway pressure increased to $40 \mathrm{cmH} 2 \mathrm{O}$. On auscultation of the patient's chest, bilateral rhonchi were present. A diagnosis of anaphylaxis was made. A 200- $\mu$ g bolus of adrenaline was administered intravenously to the patient, followed by an infusion of $500 \mu \mathrm{g} / \mathrm{hr}$. Hydrocortisone sodium (100 mg) and chlorpheniramine maleate were administered intravenously. The blood pressure gradually improved and in the next two hours, the patient's SpO2 increased to 95\% and on auscultation of bilateral chest normal vesicular breath was present, and the systolic blood pressure increased to $100 \mathrm{mmHg}$. Partial cystectomy and marsupialization was then performed successfully. After spontaneous respiration was noted Reversal (neostigmine + glycopyrrolate) was given and extubation was done. The patient was then moved to a post-anesthesia care unit(PACU) Adrenaline infusion at the rate of $500-1200 \mu \mathrm{g} /$ hour was given for 24 hours and gradually tapered.

Over the next 24 hours, the inotropic dose was gradually decreased and then stopped. The patient was discharged after one week.

\section{DISCUSSION}

It has been estimated that anaphylaxis is responsible for one life-threatening situation in every 5 to 10,000 anesthetic procedures, and that once a reaction starts, the mortality rate is $3 \%$ 6\%. ${ }^{1}$ Infection with Echinococcus granulosus or Echinococcus multilocularis leads to cystic lesions in the liver and lungs. During surgical removal of the hydatid cyst, it may get ruptured, releasing highly antigenic contents in circulation, which causes IgE-mediated anaphylactic reactions. Some reports have cited a $0.2 \%-3.3 \%$ incidence of anaphylactic shock following surgical removal of hydatid cysts. ${ }^{1,2}$

In this case, the hemodynamic and respiratory problems could be primarily related to anaphylaxis due to hydatid cyst contents. Other causes may be due to antibiotics, muscle relaxants. Sudden hemodynamic collapse occurred during the handling of hydatid cyst contents and early diagnosis and prompt treatment resulted in recovery from the catastrophe.

During the operation of hydatid cyst we should always consider the possibility of an anaphylactic or anaphylactoid reaction when there is sudden or severe hypotension and tachycardia. Bronchospasms occur less than half of the time under general anesthesia, and skin and mucosal presentations may be late or obscured in patients undergoing surgery. In the management of such cases, adrenaline is the drug of choice. ${ }^{1}$ In addition, inhalation anesthetics should be stopped, 100\% oxygen administered and the intravascular volume replenished with crystalloid.

As various literatures recommends of giving prophylaxis against anaphylaxis, event which occurred in our case would have been avoided. $\mathrm{H} 1$ and $\mathrm{H} 2$ antagonists may have been given prophylactically. ${ }^{4}$ Extubation of patient was done 
after extubation criteria was met.

We conclude that while managing the case of Hydatid cyst an anaphylactic reaction has to be taken into serious consideration, especially in the event of a sudden hemodynamic collapse.

And an intubated patient with early an early diagnosis and correct treatment are essential to ensure a favorable patient outcome.

\section{Conflict of Interest: None}

\section{REFERENCES}

1. Kir A, Baran E. Simultaneous operation for hydatid cyst of right lung and liver. Thorac Cardiovasc Surgeon 1995; 43: 62-4

2. Goel MC, Agarwal MR, Misra A. Percutaneous drainage of renal hydatid cyst: early results and followup. Br J Urol 1995; 75: 724-8

3. Altinors N, Senveli E, Donmez T, Bavbek M, Kars Z, Sanli M. Management of problematic intracranial hydatid cysts. Infection 1995; 23: 283-7

4. Kambam JR, Dymond R, Krestow M, Handte RE. Efficacy of histamine $\mathrm{H} 1$ and $\mathrm{H} 2$ receptor blockers in the anesthetic management during operation for hydatid cysts of liver and lungs. South Med J. 1988;81:1013 